\title{
Left atrial myxoma
}

Susie Layton was 60 when she noticed increasing breathlessness, fatigue, and chest pain. A left atrial myxoma was subsequently excised. She was discharged home after five days, which she believes was too early

\section{Susie Layton patient ${ }^{1}$, David P Ripley cardiology registrar and advanced imaging fellow ${ }^{2}$, Nick G Bellenger consultant cardiologist ${ }^{2}$}

${ }^{1}$ Seaton, Devon, UK; ${ }^{2}$ Royal Devon and Exeter Hospital, Exeter EX2 5DW, UK

This is one of a series of occasional articles by patients about their experiences that offer lessons to doctors. The BMJ welcomes contributions to the series. Please contact Peter Lapsley (plapsley@bmj.com) for guidance.

I was a seemingly healthy 60 year old working as a part time frame conservator. About three months before my diagnosis, I noticed being short of breath, particularly when using the stairs and climbing hills with my dog. I also experienced dizziness; felt generally tired, which I put down to aging; had occasional night cramps; and saw "stars" when bending; and I once collapsed at a supermarket. In addition, I was referred to an ear, nose, and throat surgeon in January 2011 for vocal cord weakness, as I was constantly clearing my throat especially when speaking on the telephone. A magnetic resonance imaging scan of my brain revealed nothing abnormal.

The week before my diagnosis I noticed increasing tiredness together with a dull ache on the left side of my chest. The day before I consulted my doctor I was walking on the flat with a friend. She persuaded me to seek help because she was concerned that my breathlessness was not caused by my asthma but possibly by my heart.

\section{Diagnosis, waiting time, and results}

My doctor arranged for a series of blood tests and electrocardiography to be carried out the same day at the surgery. He subsequently told me that he had called an ambulance as there were gross irregularities on the electrocardiogram and that he suspected ischaemic heart disease. I remember thinking he must be over-reacting because my chest pains were not that intense and I was shocked by his decision to call an ambulance. I was taken to the Royal Devon and Exeter Hospital, where I had further blood tests, was interviewed by a doctor, and had chest radiography.
I was then transferred to a ward where the admitting consultant told me that all the test results were negative, but that he would request an urgent echocardiography for suspected cardiomyopathy. I was then discharged and told to wait for an outpatient appointment. The shortness of breath became increasingly worse and I found myself resting most afternoons. At this point I realised there was something very wrong, since prescribed diuretics were making no difference to the symptoms. After a few days I received a phone call giving me an appointment for echocardiography. I was seen within the week. The feelings I experienced on the day of this diagnostic test were ones of fear but anticipation that I would be given an accurate diagnosis. I remember the technician's face when she said, "We can now give you a clear diagnosis for your shortness of breath." The relief I felt was enormous. I was dreading the confirmation of cardiomyopathy, never thinking what was next to come.

The cardiology registrar confirmed I had a "mass" in the left atrium called a myxoma, which would need to be excised at the cardiothoracic centre in Plymouth. He told me that I would be admitted immediately for a few more tests before transfer.

While awaiting transfer, many thoughts entered my mind, one of which was why did I leave this so long before doing anything about the symptoms? I realise in hindsight that I was petrified this was a condition that was never going to get better, so I pretended that it was not there. The surgery was going to involve extensive surgical intervention, cardiopulmonary bypass, collapsing of the lungs, a potential blood transfusion, a long recovery, and a fair bit of pain. Never once did I consider I would not recover.

That night I was taken to the coronary care unit at the cardiothoracic centre. I recall the ear piercing noise of the monitors all night long. A nurse supervised me, two doctors took long medical histories, and finally an anaesthetist arrived. 


\section{Surgery and recovery}

The following day the cardiothoracic surgeon saw me. He explained his proposed course of action and that he would phone my husband when the operation was over.

The next few days after surgery were difficult because of the pain, disorientation, and discomfort of being hooked up to drains. I was transferred to a ward from where my recovery was reasonably fast. Throughout my stay I felt great admiration for my carers but was aware of the huge pressure they were under and the need to discharge quickly.

\section{Care at home}

After five days I was discharged home. My husband is in his 70 s, has osteoarthritis, and found the prospect of caring for me daunting. I, on the other hand, was desperate to be at home, in my own bed, and trying to regain a sense of normality. It is a difficult balance - the sole carer trying to do the right thing and the patient keen to get back to "normal" as soon as possible. The recovery from open heart surgery was slow, painful, and sometimes depressing. I made myself type my own patient journey as a cathartic process almost as soon as I arrived home and sent it to family members and friends. The sense of shock and fear from them was palpable. Shock from the diagnosis and fear that I would not survive.

I do feel I was discharged too early. The move towards early discharge seems huge, which is fine when patients are supported and local hospitals have outreach, but in my case, with the exception of visits from the district nurse to monitor my anticoagulants (and that's only because I said I felt I could not attend the practice) there was no support. My husband did speak to my doctor about my discharge and the possibility of a period of admission to hospital to help with recuperation and was told that there was no infrastructure available.

As far as contact with health professionals was concerned this was very much at my request. My doctor did not visit me.

However I telephoned him a couple of times to discuss better pain management. I attended the local surgery once at the beginning of my recovery for a check of my anticoagulation, but insisted a district nurse visited me at home because I truly felt too ill to make the effort required. I also did not want to be sitting in a car as the seat belt was far too painful across my healing sternum. As soon as I felt able to I did attend the surgery for my anticoagulants to be monitored.

My recovery has been reasonably unproblematic, although the discharge medication of paracetamol for pain management was not adequate, particularly given the major surgery I had undergone and that I had required a morphine pump on the ward. I was persuaded by my doctor to consider tramadol, which was indeed more effective. I was off all pain relief by nine weeks and any treatment by 12 weeks.

At the postoperative appointment at seven weeks the biopsy report showed a left atrial myxoma. The results of electrocardiography and chest radiography were normal. I required no follow up.

I realise how fortunate I am to have had a reasonably speedy diagnosis, which helped to save my life. Perhaps my general state of fitness and health was also a bonus, but with hindsight if I had waited much longer I fear the outcome would not have been so positive. I am now symptom-free and able to live my life without shortness of breath. I am now walking and climbing hills, and, while being careful and still tired, now consider my daily routine normal rather than a nightmare, unlike before surgery.

DPR thanks the Gawthorn Cardiac Trust for its support.

Competing interests: All authors declare no support from any organisation for the submitted work; no financial relationships with any organisations that might have an interest in the submitted work in the previous three years; no other relationships or activities that could appear to have influenced the submitted work.

Provenance and peer review: Not commissioned; not externally peer reviewed.

Accepted: 18 June 2013

Cite this as: BMJ 2013;347:f4430

๑ BMJ Publishing Group Ltd 2013 


\section{Clinician's perspective}

Cardiac myxoma is the most common benign primary cardiac tumour. It usually develops in the left atrium (75\%) and less commonly in the right $(15-20 \%)$, typically attached to the interatrial septum. Ventricular myxomas are rare and those that involve the heart valves are even rarer (accounting for $<1 \%$ ). A few cases present as the Carney complex, characterised by myxomas, hyperpigmented skin, and extracardiac tumours. Presentation varies depending on the size, location, and mobility of the tumour. Some tumours produce no symptoms, whereas non-specific constitutional symptoms of fever, fatigue, arthralgia, myalgia, and weight loss make the diagnosis difficult. Mrs Layton presented after developing symptoms of intracardiac flow obstruction (dyspnoea and presyncope) as the tumour grew and intermittently occluded the mitral valve during diastole.

Myoxmas can occur at any age but typically present between 30 and 60 years and are twice as common in women as in men. They represent an embolic risk in $30-40 \%$ of cases, most usually systemic embolism (as most are located in the left atrium). The risk of embolism is

independent of size, as small tumours may be composed of extremely friable tissue. Sudden cardiac death may result from either complete obstruction of the mitral valve orifice or myocardial infarction resulting from coronary artery emboli.

Examination can reveal both diastolic and systolic murmurs, and in some a "tumour plop" may be audible as the mass passes through the atrioventricular valves. Electrocardiography is non-specific and echocardiography is the main imaging modality for diagnosis. Advanced imaging techniques such as tissue characterisation sequences with cardiac magnetic resonance imaging can be useful, and high spatial resolution of multidetector cardiac computed tomography allows identification of small tumours and calcium, which may point towards a diagnosis.

Mrs Layton describes the relief in receiving a clear diagnosis, followed by the daunting prospect of major cardiac surgery. She was rapidly transferred to a cardiac surgical centre and underwent surgery within 48 hours, which gave her and her husband little time to psychologically prepare for the risk involved or the immense task ahead. Urgent surgical referral and intervention was essential owing to the continued risk of embolism and sudden cardiac death. Cardiac surgery for atrial myxoma is the treatment of choice, with low surgical mortality, good long term outcome measures, and an extremely low recurrence rate. Survivors return to their preoperative level of daily activity usually within a short period of surgery.

The postoperative period is a difficult challenge for both patients and their families and carers. There is a role for cardiac rehabilitation which is well established after myocardial infarction, coronary artery bypass grafting, and percutaneous coronary intervention, although this ought to be extended to all undergoing non-coronary cardiac surgery. Patients benefit from referral to the cardiac rehabilitation team before surgical intervention, helping them to adjust to their situation and psychological state. Cardiac rehabilitation reduces mortality, myocardial infarction, and readmission rates and improves functional capacity and perceived quality of life. Furthermore, it allows seamless integration with the primary care teams.

\section{Useful resources for patients and health professionals}

British Heart Foundation (www.bhf.org.uk)—contains an information leaflet on atrial myxoma

British Association for Cardiovascular Prevention and Rehabilitation (www.bacpr.com)-a multidisciplinary body representing and serving the interests of professionals involved in cardiac rehabilitation 